\title{
DERECHO DE PROPIEDAD Y POSTERGACIONES DE PERMISOS URBANÍSTICOS
}

\author{
Arturo Fermandois Vöhringer* 1
}

\begin{abstract}
RESUMEN: Este trabajo indaga por el sentido jurídico de la institución de las postergaciones de permisos urbanísticos consagrada en el artículo 117 de la Ley General de Vivienda y Urbanismo y su compatibilidad con la Constitución. Luego, plantea y demuestra su carácter excepcional. En este proceso revisa esclarece y precisa los requisitos formales y sustanciales que el texto legal y la Carta Fundamental exigen a la autoridad administrativa para decretar esta verdadera medida precautoria de carácter administrativo, que constriñe gravemente el derecho de propiedad.
\end{abstract}

Palabras clave: permisos urbanísticos, derecho de propiedad, Ley General de Vivienda y Urbanismo, expropiación regulatoria.

ABSTRACT: This paper deals with the constitutionality of a special administrative mechanism provided by article 117 of the Chilean Urban Law, that allows local authorities to delay construction permits and freeze urban zones from regular developments. The author reviews all formal and substantive legal requirements that justify this exceptional measure, which severily restricts property rights and may convert into a regulatory taking before the Chilean Constitution.

Key words: construction permits, property rights, Ley General de Vivienda y Urbanismo, regulatory taking.

\section{INTRODUCCIÓN}

Hace casi diez años se comentó en esta misma Revista -a propósito de un fallo- la institución de las postergaciones de permisos de subdivisión, loteo o urbanización predial y construcciones, conocida también como congelamientos urbanisticos ${ }^{2}$. Este peculiar instrumento urbanístico está contemplado en el artículo 117 del Decreto con Fuerza de Ley $\mathrm{N}^{\circ}$ 458, del Ministerio de Vivienda, de 1975, Ley General de Urbanismo y Construcciones.

Aquel comentario de 1998 llamó la atención sobre la escasa fiscalización de los requisitos materiales que la ley exige para la procedencia del llamado congelamiento urbanístico; analizó sus efectos y los derechos constitucionales que potencialmente po-

\footnotetext{
* Profesor de Derecho Constitucional, Pontificia Universidad Católica de Chile.

${ }^{1}$ El autor agradece la colaboración prestada para este trabajo por Gonzalo Candia Falcón, profesor instructor de la Facultad de Derecho de la P. Universidad Católica de Chile.

2 En ese artículo comentamos el fallo del recurso de protección "Viviendas 2000 Limitada con Alcalde de Municipalidad de Lo Barnechea" y criticamos "[la evasión por parte de las Cortes] de un análisis prolijo de la arbitrariedad del acto funcionario [que decreta un congelamiento] confundiendo peligrosamente la existencia de la facultad legal con el uso razonable, justo y fundado de la misma" (FERMANDOIS, 1997, p. 247).
} 
drían verse infringidos por la autoridad municipal al decretarlo. Este artículo profundizará e intensificará esa línea, revisando ante la doctrina y jurisprudencia actualizada los requisitos legales de los congelamientos, su justificación, sus vulnerabilidades, contradicciones y procedencia ante nuestro sistema jurídico-constitucional.

El trabajo se estructurará con tres apartados iniciales, en los que se analizará el concepto mismo del congelamiento urbanístico, su presunta justificación y utilidad, y su eventual armonía o discordancia con el conjunto de derechos y garantías que, actualmente en 2006, ofrece nuestro sistema jurídico.

Un análisis como este se justifica por cuanto la fuente legal de los congelamientos data desde 1975, habiendo permanecido el precepto legal que los creó (Art. 117 del DFL $\mathrm{N}^{\circ} 458$ ) inmodificado durante más de 30 años. Durante este vasto período de tres décadas se refundó por completo el ordenamiento legal chileno, incluyendo la promulgación de una nueva Constitución Política, una nueva legislación municipal (Ley Orgánica Constitucional $\mathrm{N}^{\circ} 18.696$ ), y una nueva legislación administrativa (ley $\mathrm{N}^{\circ} 19.880$, de 2003 entre otras leyes).

Además, en estos 30 años se crearon nuevos instrumentos de control administrativo, recursos judiciales como el de protección (art. 20 de la Constitución), nuevos tribunales y está emergiendo una nueva filosofía de protección a los derechos fundamentales, inexistente en 1975.

De todo esto se sigue que lo que pudo ser admisible jurídicamente en 1975, hoy probablemente no lo es. El artículo indagará en plausibles zonas de sustento o de descarte de esta tesis, en particular respecto de las postergaciones de permisos.

En un cuarto apartado se descenderá de los conceptos a la práctica. Revisaremos ahí los requisitos legales de fondo y de forma para decretar un congelamiento y para prorrogarlo. Luego, se analizará y comentará la jurisprudencia de las Cortes y de la Contraloría que han interpretado estos requisitos y se emitirá una opinión sobre el estado actual de la fiscalización de esos requisitos.

Finalmente, en un último punto se ofrecerán las conclusiones que surgen de nuestro trabajo.

\section{EL SENTIDO Y JUSTIFICACIÓN DEL MECANISMO DEL CONGELAMIENTO DEL ARTÍCULO 117 DE LA LEY GENERAL DE URBANISMO Y CONSTRUCCIONES}

Este apartado estará destinado a indagar por la lógica, propósito y justificación legal del mecanismo de las postergaciones o congelamientos.

\subsection{LOS CONGELAMIENTOS DE LA LGUC Y LA PROGRESIVA SENSIBILIZACIÓN CONSTITUCIONAL EN LAS LIMITACIONES URBANÍSTICAS \\ La Ley General de Urbanismo y Construcciones admite tres clases de congela- mientos urbanísticos. La primera corresponde al llamado congelamiento genérico, del artículo 62 de la misma ley. Este consiste en que "los terrenos cuyo uso no se conformare con los instrumentos de planificación territorial correspondientes, se entenderán congelados".}


Este congelamiento no es otra cosa que la ratificación de lo obvio; el dueño de un terreno no podrá - por regla general- aumentar el volumen de construcciones autorizado por el plan regulador para dicho uso de suelo.

La segunda categoría de congelamientos es la controvertida declaratoria de utilidad pública de inmuebles ${ }^{3}$. En los terrenos sometidos a esta declaración, “...no se podrá aumentar el volumen de las construcciones existentes a la fecha de aprobación del respectivo plan regulador..." por los plazos máximos que la LGUC autoriza.

La declaratoria de utilidad pública del artículo 59 de la LGUC, sin usar el verbo congelar, introduce una prohibición que produce jurídicamente ese mismo efecto, ilustrado tan correctamente por aquella voz. Fuertes discusiones sobre su inconstitucionalidad, arbitrariedad, discriminación y desigualdad en la carga pública, llevaron al Congreso en 2001 a aprobar la ley $\mathrm{N}^{\circ} 19.744$.

La ley 19.744 impuso plazos máximos a la declaratoria de utilidad pública por el Estado. Los otrora plazos perpetuos se transformaron en términos máximos de diez y de cinco años. Dentro de ellos, el Estado debe ahora expropiar el correspondiente terreno o, a su vencimiento, se levantará inexorablemente la prohibición que pesa sobre el inmueble.

La filosofía de la ley $\mathrm{N}^{\circ} 19.744$ es interesante para este trabajo sobre congelamientos. En efecto, su sola aprobación da cuenta del proceso de progresiva sensibilización constitucional en materia urbanística. En el pasado jamás se cuestionó la declaratoria perpetua de utilidad pública; era simplemente una carga del propietario, quien debía aceptar y soportar.

Hoy, legisladores y jueces están entendiendo progresivamente que la Constitución prohíbe infringir la garantía de la igualdad ante las cargas públicas (art. $19 \mathrm{~N}^{\circ} 20$ de la Constitución). Entienden también que un congelamiento, una declaratoria de utilidad pública o una declaración de monumento nacional, produce exactamente ese efecto: para la utilidad de todos, se exige el sacrificio de uno o unos pocos en su dominio.

La Corte Suprema ya declaró inconstitucional en 2004 la Ley 17.288, de Monumentos Nacionales. Poco antes, la citada ley 19.744 colocó plazos definidos -aún largos- a la afectación de utilidad pública. Ambos hechos reflejan el mismo proceso y son signos de los tiempos. Vienen a colocar en el tapete a la ley urbanística en general y sus instrumentos excesivos de limitación.

La lección entonces es que tanto la LGUC, de 1975, como las leyes especiales de la época tienen que aprobar los estándares actuales de respecto a derechos fundamentales ${ }^{4}$. Hemos comentado sobre este proceso y casos ${ }^{5}$. Otros autores, que a la vez han sido funcionarios del MINVU, también destacan los defectos de la ley en esta materia, como Rajevic, quien sostiene que:

"Las normas vigentes contienen supuestos que afectan de manera bastante intensa a algunos propietarios. Particularmente injusto es el caso de los congelamientos derivados de determinaciones urbanísticas que cambian el uso de suelo de un terreno afectándolo

\footnotetext{
3 Decreto con Fuerza de Ley No 478, de 1976.

4 Inmobiliaria Maullín con Fisco (2004).

${ }^{5}$ FERMANDOIS (2005) pp. 19-55.
} 
a un uso público que no se concreta nunca, pero impiden al propietario sacar provecho de su bien"':

En fin, resulta nítido que estamos en medio de un saludable proceso de sensibilización jurídica sobre los congelamientos o prohibiciones urbanísticos, entendido como una mayor toma de conciencia de su excepcionalidad, que es lo que revisaremos en el párrafo siguiente.

Así las cosas, revisemos la fuente legal de la tercera y última clase de congelamientos, las llamadas postergaciones de permisos, que emana del artículo 117 de la LGUC.

Dispone esta norma lo siguiente:

Artículo 117.- Los permisos de subdivisión, loteo o urbanización predial y de construcciones podrán postergarse hasta por un plazo de tres meses, cuando el sector de ubicación del terreno esté afectado por estudios sobre modificaciones del Plan Regulador Intercomunal o Comunal, aprobados por resolución del Alcalde. Esta postergación deberá ser informada previa y favorablemente por la Secretaría Regional correspondiente del Ministerio de Vivienda y Urbanismo.

En caso necesario, el citado plazo de tres meses podrá ser prorrogado hasta completar un máximo de doce meses. La prórroga se dispondrá por decreto supremo del Ministerio de Vivienda y Urbanismo dictado "por orden del Presidente de la República" o por resolución del Secretario Regional Ministerial de Vivienda y Urbanismo respectivo, según se trate de estudios sobre modificaciones de un Plan Regulador Intercomunal o de un Plan Regulador Comunal, en su caso. Tanto el decreto supremo como la resolución se publicarán en el Diario Oficial y en algún diario de los de mayor circulación en la comuna.

Abordemos, pues, el específico sistema de postergaciones de permisos, que emana del citado artículo de la LGUC.

\subsection{FUNDAMENTO Y FILOSOFÍA DE LAS POSTERGACIONES DE PERMISOS O CONGELAMIENTO DEL ART. 117 DE LA LGUC}

Esta tercera clase de congelamientos urbanísticos, propiamente conocida como congelamiento o postergación de permisos, está recogida en el citado artículo 117 de la Ley General de Urbanismo y Construcciones.

Como lo dice su verbo rector, el mecanismo en estudio autoriza al alcalde para "postergar" los permisos básicos emanados del derecho de propiedad sobre un inmueble. Estos abarcan las facultades básicas de subdividir, lotear y construir.

Por su naturaleza, estos congelamientos detienen el desarrollo urbano en una comuna, al suspender el otorgamiento de estos permisos hasta por un plazo total de 12 meses. En consecuencia, afectan por la vía de la privación temporal, al menos dos garantías constitucionales abstractas: el derecho de propiedad y el derecho a desarro- 
llar actividades económicas (artículo 19 números 24 y 21 de la Constitución). Tanto los propietarios como las empresas inmobiliarias que desarrollan legítimamente actividades económicas que no se oponen a la moral, las buenas costumbres ni a la seguridad nacional, deben resignar su derecho constitucional por completo, al menos temporalmente.

Potencialmente, también, se tocan las garantías de la igualdad a la ley y la no discriminación arbitraria en materia económica en el trato que deben dar el Estado y sus organismos (números $2^{\circ}$ y $22^{\circ}$ del art. 19).

No obstante, el legislador ha autorizado la aplicación de esta medida excepcional. ¿Cuál es su fundamento? Conviene revisarlo, porque en este punto comienzan las falencias de alguna jurisprudencia de las cortes.

El fundamento original de estas postergaciones o congelamientos es evitar las especulaciones inmobiliarias sobre sectores de una comuna cuyas normas urbanísticas serán afectadas por una inminente modificación al Plan Regulador Comunal. El legislador ha querido evitar que, ante tal inminente modificación, se obtengan permisos de última hora que resten armonía a las modificaciones urbanísticas a aplicarse ${ }^{7}$.

$\mathrm{Al}$ respecto dice Cancino que:

"En todo caso, la utilidad de esta norma es evidente, dado que aquellos que buscan desarrollar un proyecto se apresurarán a presentarlo antes de que el nuevo plan esté vigente a fin de regirse por la normativa aplicable al momento del anteproyecto o del permiso de edificación, lo que obviamente va a perjudicar todo el proceso de planificación urbana"s.

Esta y no otra sería la justificación lógica del congelamiento del artículo 117: evitar que ante un cambio inminente del instrumento de planificación territorial, se presenten proyectos artificialmente generados que malogren la planificación urbana futura.

Parece lógico, pero en realidad no existen antecedentes fidedignos en la historia del DFL 458 que permiten confirmar cuál es la lógica de una medida tan gravosa y excepcional. A falta de pruebas, debemos estarnos a esta natural explicación, aceptada por la escasa doctrina y por nosotros mismos.

En efecto, ya en 1998 habíamos afirmado que el congelamiento solo se justificaba como elemento estabilizador ante modificaciones inminentes al Plan Regulador. Nos basamos en la frase de la ley que exige que "...el sector del terreno esté afectado por estudios sobre modificaciones al Plan Regulador Intercomunal o Comunal..." .

¿Cómo se prueba que existe una modificación inminente al Plan Regulador? La ley exige la existencia de estudios en curso, aprobados por resolución del alcalde.

\footnotetext{
7 El artículo 117 de la Ley General de Urbanismo y Construcciones autoriza el congelamiento, en consecuencia, solo cuando "el sector de ubicación del terreno esté afectado por estudios sobre modificaciones del Plan Regulador Intercomunal o Comunal, aprobados por resolución del Alcalde”.

${ }^{8}$ CANCINO (2005) p. 169.

${ }^{9}$ Fermandois (1997) p. 245.
} 


\subsection{ESTUdIOS COMO ÚNICO FUNDAMENTO DE LAS POSTERGACIONES DE PERMISOS}

Es así como el único fundamento legal, racional y constitucional para la aplicación de una medida tan excepcional, y que deslegitima el ejercicio de derechos fundamentales por un breve período, es la existencia de estudios que respalden la modificación al Plan Regulador.

La fiscalización de este simple requisito, sin embargo, suele pasar desapercibida ante la más visible la facultad legal de postergar los permisos, conferida al alcalde con informe previo del Secretario Regional Ministerial de Vivienda respectivo. El texto del artículo 117 de la LGUC exige el informe previo favorable del SEREMI, y con ello el Decreto Alcaldicio podría formalmente dictarse.

Normalmente los reclamos de los afectados no están dirigidos a la ilegalidad de la medida, entendida como ejercicio de una atribución formal por el alcalde, quien suele obtener informe previo y favorable del seremi. Los agravios se acumulan por la vía de la arbitrariedad, análisis que las cortes en el pasado solían evadir.

\section{LA EXCEPCIONALIDAD CONSTITUCIONAL DEL CONGELAMIENTO URBANÍSTICO}

El congelamiento del artículo 117 de la LGUC configura un régimen jurídico excepcionalmente gravoso para el propietario de un inmueble. Tan excepcional, que hay serias dudas sobre su constitucionalidad de fondo.

Es decir, es tal su intensidad jurídicamente compresora del dominio, que cabe legítimamente preguntarse si un mecanismo que autorice para suspender del todo las facultades más importantes del uso del dueño sobre su bien raíz, por plazos que pueden alcanzar hasta un año, sea compatible hoy con el artículo $19 \mathrm{~N}^{\circ} 24$, incisos primero, segundo y tercero de la Constitución ${ }^{10}$.

\subsection{CONTEXTO DE LA EXCEPCIONALIDAD}

En efecto, el congelamiento suspende los atributos básicos del dominio sobre inmueble, y en particular el ius aedificandi-la facultad de edificar- por plazos constitucionalmente desproporcionados y comparativamente sorprendentes.

En cuanto a esto último, piénsese que los plazos más extensos que autoriza la Constitución para regímenes de excepcionalidad van desde 30 hasta 90 días, y solo bajo los llamados Estados de Excepción Constitucional. Considérese además que la declaración de estos estados es muy estricta e intervienen las más altas autoridades del Estado, porque contrarían el principio del libre disfrute de los derechos constitucionales. En este sentido, el artículo 39 de la Constitución dispone que:

"El ejercicio de los derechos y garantías que la Constitución asegura a todas las personas solo puede ser afectado bajo las siguientes situaciones de excepción..."

${ }^{10}$ Véase criterios como el emanado del fallo caso "Rentas Vitalicias", del Tribunal Constitucional, de 21 de agosto de 2001, rol No 334 . 
Una vez declarados los estados de excepción, los plazos son breves. El Estado de emergencia, por ejemplo, "no podrá extenderse por más de quince dias, sin perjuicio de que el Presidente de la República puede prorrogarlo por igual periodo", las que deben autorizarse por el Congreso Nacional (artículo $42 \mathrm{CPR}$ ). Es cierto que el estado de catástrofe podría llegar a extenderse hasta un año, pero en un régimen muy excepcional y siempre autorizado por el Congreso mismo (Art. 41).

De manera que los principios constitucionales vigentes hoy exigen plazos breves, motivos calificados y altas autoridades interviniendo cuando se trata de afectar derechos y garantías.

Ante estas realidades, los plazos del congelamiento urbanístico son desproporcionados e injustificados. Probablemente se explican una vez más por el año de la ley, 1975, anterior a la Constitución de 1980 y anterior incluso al Acta Constitucional N² 2, de 1976.

Es efectivo que los estados de excepción constitucional tienen una dimensión territorial más amplia que el congelamiento y una lógica más global de restricciones o suspensiones. Pero también es efectivo que la Constitución es un todo armónico, como lo ha dicho reiteradamente el Tribunal Constitucional, no pueden existir contradicciones entre dos normas de la Ley Suprema ${ }^{11}$.

En este sentido, si el artículo $43^{\circ}$ de la Carta solo autoriza que se impongan limitaciones al derecho de propiedad durante un Estado de Asamblea (guerra), y por plazos breves, es absurdo pensar que el artículo $19^{\circ} \mathrm{N}^{\circ} 24$ de la Constitución pueda facultar a la ley para que autoridades inferiores, como alcaldes y seremis, decreten limitaciones graves al derecho de propiedad por plazos de hasta un año.

Pero volviendo a la excepcionalidad de fondo de las postergaciones de permisos, y antes de revisar la doctrina y la jurisprudencia en esta materia, hagamos un ejercicio de simple lógica jurídica:

Premisas:

i. Si el propietario de un inmueble dispone por definición de las facultades esenciales de uso, goce y disposición sobre su terreno, constitucionalmente garantizadas (artículo $19 \mathrm{~N}^{\circ} 24$, inciso tercero CPR);

ii. Si en la propiedad inmobiliaria la facultad de uso se traduce esencialmente en el ius aedificandi, esto es, en el derecho a construir en el inmueble aquello que no contraríe su naturaleza y que se halle autorizado ${ }^{12}$;

iii. Si las normas vigentes sobre planificación territorial autorizan a su dueño para construir determinadas edificaciones, o subdividir, lotear o urbanizar (arts. $34 \mathrm{y}$ 57 LGUC);

iv. Si esas normas urbanas solo pueden ser alteradas mediante modificaciones formales a los planes reguladores comunal o intercomunal, instrumentos que son

11 Así ha sido invariablemente sostenido por el Tribunal Constitucional, a contar de su sentencia rol No 33, de 24 de septiembre de 1985 .

12 "No obstante, en mi opinión, la legislación española no ha escindido nunca el ius aedificandi del dominio. El propietario del suelo, por serlo, cuenta entre sus facultades con el derecho a edificarlo, y esto no ha sido cuestionado por la legislación española” (TEJEDOR, 1999, p. 409). 
objeto de una tramitación exigente, pública y multisectorial (concejo municipal, participación ciudadana, Contraloría General, etc.);

v. Si ese cambio de planificación territorial aún no se verifica;

Entonces, la conclusión es forzosa: la suspensión (tenuemente llamada "postergación” por la ley) del derecho a edificar, subdividir, urbanizar o lotear, configura una situación legal y constitucionalmente excepcional.

\subsection{CONSECUENCIA DE LA EXCEPCIONALIDAD: INTERPRETACIÓN RESTRICTIVA. DOCTRINA}

La doctrina y jurisprudencia administrativa de la Contraloría avalan la excepcionalidad de los congelamientos. La consecuencia jurídica de la excepcionalidad es la estrictez en la interpretación de los requisitos: en la duda, el legislador prefiere negar el congelamiento. Es decir, el funcionario correspondiente -alcalde o seremi- debe indagar con profundidad y adquirir la convicción que los requisitos legales están cumplidos plenamente.

Dice el Dictamen N 10.694 de la Contraloría General de la República, de 28 de marzo de $1994^{13}$, sobre el congelamiento del art. 117 citado:

"Pues bien, en la medida que la norma transcrita afecta el ejercicio de un derecho amparado por la Constitución Politica, como lo es el de propiedad, es excepcional y de interpretación restringida..."

Poco antes, en 1989, con ocasión de dictaminar la ilegalidad de un Decreto alcaldicio, el contralor había afirmado:

“...cabe señalar que en la situación de que se trata tanto la dictación de los Decretos Alcaldicios números... como en el Decreto $N^{\circ} 178$, de 1988, del Ministerio de Vivienda y Urbanismo, no se ajustan a derecho y afectan al derecho de propiedad garantizado por el artículo 19, $N^{\circ} 24$, de la Constitución Política del Estado, siendo improcedente que se haga uso de la facultad excepcional contemplada por el artículo 117 del Decreto $N^{\circ} 458$, de 1976, del Ministerio de Vivienda y Urbanismo..." 14 .

Es así como la Contraloría ha sido nítida en destacar la excepcionalidad de las postergaciones. Veremos que las cortes judiciales también han advertido sobre esta natural característica de este instrumento reductor del derecho de propiedad.

Antes de revisar lo fallado por las cortes, verificaremos los requisitos legales de los congelamientos.

\footnotetext{
13 Dictamen No 10.694 de la Contraloría General de la República, de 28 de marzo de 1994 (destacado es nuestro).

14 Dictamen No 4.358, de 9 de febrero de 1989, de la Contraloría General de la República (destacado es nuestro).
} 


\section{LOS REQUISITOS DEL CONGELAMIENTO URBANÍSTICO}

Analizaremos en este capítulo los requisitos legales del congelamiento y cómo deben estos fiscalizarse debidamente.

Existen dos clases de requisitos para que se decrete una postergación de permisos al amparo del artículo 117 de la LGUC: de forma y de fondo.

Son requisitos de forma aquellos que apuntan a los documentos, trámites y formalidades que exige la ley para la procedencia del congelamiento.

Son requisitos de fondo aquellas exigencias que materializan conforman la justificación de propósito de la ley, y que no son necesariamente apreciables por el mero análisis de los requisitos de forma.

\subsection{Requisitos DE FORMA DE LOS CONGELAMIENTOS}

Hay que distinguir dos situaciones: el congelamiento inicial y la prórroga del congelamiento.

\subsubsection{Postergación Inicial}

Del texto del inciso primero del artículo 117 se desprende con claridad que los requisitos de la postergación inicial de permisos son los siguientes.

a) Decreto alcaldicio, que decreta el congelamiento.

b) Informe favorable del seremi del MINVU, emitido formalmente por medio de un acto administrativo válido.

c) Resolución del alcalde aprobatoria de Estudios sobre modificación al Plan Regulador.

d) Publicación del decreto en el Diario Oficial y en un diario de entre los de mayor circulación de la comuna.

\subsubsection{Prórroga de Congelamiento}

Para prorrogar la postergación, del inciso segundo del artículo $117^{\circ}$ se infieren los siguientes requisitos:

a) Solicitud formal de prórroga del alcalde al seremi. Se desprende del texto del artículo 117 de la LGUC. Cabe la duda si el SEREMI estaría facultado para prorrogar directamente por sí, sin requerimiento en tal sentido del alcalde. Nos inclinamos por negar tal posibilidad, en atención a la lógica del artículo 117 y a lo dispuesto en el artículo 118 , inciso $4^{\circ}$ de la Constitución, sobre autonomía municipal.

b) Resolución del seremi del MINVU. Este es acto material por medio del cual se decreta la prórroga, a menos que se trate de una prórroga de congelamientos del Plan Regulador Intercomunal, en cuyo caso la ley dispone esto se haga por Decreto Supremo, dictado "por orden del Presidente de la República"15.

${ }^{15}$ El Tribunal Constitucional, en sentencia rol No 153, de 25 de enero de 1993, ha fallado que los decretos supremos "por orden del Presidente de la República" (es decir, sin la firma del Jefe de Estado), en materia de planificación territorial, son inconstitucionales. En la oportunidad declaró la inconstitucionalidad del Decreto Supremo No 66, "por orden del Presidente de la República", del MINVU, de junio de 1992. Esto 
c) Toma de Razón de resolución por Contraloría General de la República. La resolución del SEREMI o el Decreto Supremo están sujetos al control de legalidad por la propia Contraloría.

d) Diario Oficial y Diario Comunal. La Notificación de la resolución o decreto debe hacerse en el Diario Oficial y en un diario de mayor circulación de la comuna.

\subsection{REQUiSITOS DE FONDO DE LAS POSTERGACIONES}

Nuevamente debe distinguirse entre el decreto inicial que impone la postergación de los permisos y su prórroga.

\subsubsection{Congelamiento inicial}

a) Existencia de estudios. Interpretando esta exigencia legal de forma restrictiva, al tenor de su carácter excepcional, podemos entender que esos estudios que requiere la ley deben ser:

i. Reales y actuales y no futuros o posibles. Es decir, no pueden invocarse estudios ideales, futuros, eventuales o posibles. De acuerdo al Diccionario de la Real Academia de la Lengua, algo es real cuando "tiene una existencia verdadera y efectiva";

ii. Aprobados por resolución del alcalde. Aprobación debe exhibir carácter formal, es decir, mediante el decreto correspondiente.

iii. Precisos en su territorialidad. Los estudios deben referirse a zonas determinadas y precisas y el congelamiento solicitarse solo respecto de estas zonas. Están proscritos por la jurisprudencia los congelamientos sobre zonas genéricas o indeterminadas.

iv. Coherentes en su temporalidad. No pueden solicitarse congelamientos sino cuando la modificación del Plan Regulador es inminente, a verificarse en un plazo máximo de tres meses.

Es decir, repugna a la ratio legis del congelamiento el que estos se decreten cuando no sea posible modificar el Plan Regulador sino en un futuro mediano o lejano. Ahí se estará desvirtuando la naturaleza y función de este instrumento, para ponerlo al servicio de otros fines. Así, se hace más patente su ilegalidad.

Es efectivo que la modificación al plan regulador es extensa, pero ese defecto no puede soportarlo el ciudadano en sus derechos; será la autoridad la que deberá darle celeridad al procedimiento, pero jamás le será lícito calcular inicialmente un congelamiento total de 12 meses: eso es burlar la ley.

b) Coherencia cronológica. Este es un aspecto crítico, que se analizará en detalle más adelante. La postergación de permisos debe coincidir cronológicamente con la últi-

da una idea de la época en que el DFL 458 se dictó, que es en medio de la década de 1970, cuando las categorías constitucionales de la actual Carta Fundamental no entraban en vigor. El antecedente va en abono de las severas dudas de constitucionalidad que ofrece intrínsecamente el mecanismo mismo de las postergaciones, y lo mismo ocurre para sus formalidades de prórroga, como esta. 
ma etapa previa a la vigencia del nuevo plan regulador. El congelamiento solo puede solicitarse ante la inminencia de la entrada en vigencia del nuevo plan y no puede cumplir otros fines. Esto se desprende del plazo breve de tres meses por el que la ley lo autoriza y de la prórroga autorizada solo en "caso necesario", excepcionalmente.

c) Coherencia territorial. Zonas precisas. Por último, como lo ha dicho la jurisprudencia, la postergación debe abarcar estrictamente las zonas territoriales en que el plan regulador será modificado; nada más ni nada menos. Tampoco podrán producirse superposiciones de áreas que lleven a los afectados a soportar plazos mayores a los legales.

\subsubsection{Prórroga de congelamientos}

Para las prórrogas, se añaden los siguientes requisitos:

a) Existencia de un "caso necesario". Este es el requisito fundamental de la prórroga. La ley no señala qué es un caso necesario, pero se trata de una justificación especial, excepcional, suficiente. Y lo que es más importante, debe apreciarse y ponderarse caso a caso, cada vez que se solicite. Esto exige una mínima verificación por SEREMI y Contraloría al tiempo de la toma de razón.

b) Coherencia cronológica. Son aplicables aquí las reflexiones de la letra be anterior.

\subsection{LA ARBITRARIEDAD COMO VIOLACIÓN A LOS REQUISITOS DE FONDO DE LOS}

\section{CONGELAMIENTOS}

Es evidente que el uso de un instrumento jurídicamente tan poderoso como la postergación de permisos exige razonabilidad, que es un principio jurídico. La infracción de la razonabilidad es la arbitrariedad, prohibida por la Constitución.

La arbitrariedad de un acto es la vulneración del uso razonable con que los elementos discrecionales de un poder jurídico han de ser ejercidos. El acto es arbitrario cuando, existiendo un grado de discrecionalidad conferida por la ley al funcionario para la ejecución del acto, este lo ejecuta apartándose del fin para el que la facultad fue otorgada, haciendo el acto intrínsecamente injusto.

El congelamiento o postergación de permisos será arbitrario, entonces, cuando no existan estudios en curso para modificar el Plan Regulador, cuando estos estudios no sean de la relevancia necesaria para justificar una modificación al Plan Regulador, o cuando, existiendo estudios relevantes para tal modificación, ellos recomienden la modificación de áreas o zonas mayores o bien menores a las que el Decreto Alcaldicio congeló.

Finalmente, será también arbitrario el acto cuando no sea verosímil que el Plan Regulador pueda modificarse en el breve plazo dispuesto por el congelamiento, o en el plazo total de congelamientos autorizados por la ley (12 meses) ${ }^{16}$. Expertos urbanistas afirman que es prácticamente imposible tramitar una modificación a un Plan Regulador

${ }^{16} \mathrm{Al}$ respecto, debe tenerse presente que la modificación a un Plan Regulador Comunal exige una larga tramitación administrativa, en la que intervienen el Concejo Municipal, el Seremi, el Gobierno Regional, la Comunidad y la Contraloría General de la República. Nuevos requisitos legales hacen aún más larga una modificación, como el agregado por la letra h) del artículo 10 de la Ley 19.300, que exige a estas modificaciones someterse al sistema de Evaluación de Impacto Ambiental. 
Comunal, por sencilla que parezca, en menos de dos años, en circunstancias que las postergaciones pueden decretarse por tres meses y prorrogarse hasta por 12 meses.

En efecto, toda modificación de un plan regulador es una labor ardua, compleja y cronológicamente extensa. Así lo reconocen los autores. Como dice Rajevic, tan solo considérese, como ejemplo, que en la propia Región Metropolitana al año 2000 muchas de las comunas no habían ajustado sus planos comunales al Plan Intercomunal creado en 1994. Es decir, habían transcurrido en algunos casos seis años y aún no era posible adecuar ambas normativas urbanísticas ${ }^{17}$.

Sin embargo, esa complejidad no puede significar imponer por vía administrativa al particular sacrificios que no está obligado jurídicamente a soportar; de allí que el espíritu de la ley exija a la Administración que, cada vez que considere necesario postergar los permisos, debe hacerlo solamente cuando los estudios de modificación del plan regulador comunal o intercomunal se encuentran en un estado de avance tal que puedan concluirse, en principio, dentro del plazo de tres meses que inicialmente fija el legislador.

¿Qué significa lo anterior? Significa que la autoridad no podrá decretar una postergación de permisos para "iniciar estudios" de modificación del plan regulador, sino solo para concluir aquellos que ya se venían desarrollando.

Ahora bien, ¿a quién corresponde fiscalizar que estos requisitos en torno a los estudios se verifiquen de forma efectiva y oportuna? El propio artículo 117 de la LGUC en su inciso primero in fine nos da la respuesta:

"Esta postergación deberá ser informada previa y favorablemente por la Secretaría Regional correspondiente del Ministerio de Vivienda y Urbanismo".

En cuanto será -en definitiva- el SEREMI la autoridad llamada a conocer del decreto alcaldicio de postergación de permisos y de su correspondiente justificación con el objeto de aprobarlo o rechazarlo, también será de su competencia verificar que los requisitos anteriores en relación a los estudios sean efectivos.

Como podemos apreciar el peligro de desnaturalización de los congelamientos es evidente. Las autoridades municipales pueden verse tentadas a recurrir a este mecanismo como una forma de arbitrar las disputas urbanísticas entre vecinos, entre empresas constructoras y vecinos o incluso entre miembros del Concejo Municipal, apartándose del único fundamento constitucional que legitima un régimen tan excepcional.

\section{LA JURISPRUDENCIA ADMINISTRATIVA Y JUDICIAL SOBRE CONGELAMIENTOS. PROCEDIMIENTOS, PLAZOS Y LIMITACIONES}

Las postergaciones de permisos han sido objeto de un buen número de litigios, sentencias judiciales y pronunciamientos por la Contraloría General de la República.

De estos fallos emanan ciertos valiosos criterios que han venido colocando límites al uso arbitrario del mecanismo por parte de alcaldes o seremis.

17 Véase: RAJEVIC (2000) p. 546. 
Creemos, en todo caso, que la jurisprudencia es aún tibia y no fiscaliza por ahora con profundidad y decisión los requisitos de forma y de fondo. Pero los fallos y dictámenes están bien encaminados, y para este artículo será útil comentarlos y extraer las conclusiones que de ellos emanan.

\subsection{CONTRALORÍA General de la RepúblicA}

Revisaremos los casos más relevantes llevados ante la Contraloría General de la República, y las circunstancias de cada uno.

\subsubsection{Dictamen No 4.358 (1989): Imposibilidad de decretar congelamientos indefinidos}

Una empresa recurrió a la CGR para consultar acerca de las facultades que tienen las Municipalidades para postergar nuevamente permisos de subdivisión que habían sido objeto de una postergación anterior. En el fondo, la interrogante que se efectúa es si una municipalidad puede -de acuerdo al artículo 117 de la LGUC- decretar un nuevo congelamiento sobre una misma área una vez vencida la primitiva autorización.

Para resolver la cuestión, el organismo contralor partió de la siguiente premisa: el artículo 117 de la LGUC es excepcional y, por tanto, su interpretación debe ser restrictiva. A partir de aquello, afirmó que:

"El plazo de postergación de los permisos de loteo, subdivisión o urbanización y construcciones no puede exceder de doce meses, más allá de los cuales los efectos del decreto de suspensión se extinguen por el solo ministerio de la ley".

Por tanto, para la CGR:

a) Es ilegal la dictación de un decreto municipal que contenga nuevos congelamientos transcurridos los doce meses respectivos; $y$

b) No puede burlarse el alcance de la norma dictándose un nuevo decreto de congelamiento que afecte parte del mismo sector ya sometido a suspensión. Aquello constituiría una superposición de sectores que vulneraría el espíritu de la ley.

\subsubsection{Dictamen No 10.694 (1994): Carácter inconstitucional de los congelamientos indefinidos}

En este dictamen, la CGR reitera su doctrina en torno a la excepcionalidad de los congelamientos urbanísticos y a la naturaleza restrictiva de su interpretación. Sin embargo, en este caso da un paso más y señala que esas características se deben a que el artículo 117 de la LGUC necesariamente constituye una limitación a la regla general de protección al derecho de propiedad. Por ello:

"De admitirse la posición adversa [esto es, que son procedentes los congelamientos indefinidos] ello significaría que la Administración, con breves soluciones de continuidad intercaladas podría restringir indefinidamente el derecho de propiedad en la zona afectada, sosteniendo, como ahora se hace, que se trata de [un ciclo nuevo y distinto de postergaciones de permisos]" 
Esto significaría, en buenas cuentas, que "[se dejaría] un bien fuera del comercio humano por decisiones ilegales de las autoridades administrativas", lo que a todas luces "no se ajusta a Derecho y afecta el derecho de propiedad garantizado por el artículo 19 No 24 de la Constitución Política de la República”.

5.1.3 Dictamen No 38.990 (1994): Los Decretos Supremos del Minvu que autorizan la prórroga de los congelamientos deben ser objeto del trámite de toma de razón de CGR

Consultada CGR acerca de si la resolución del seremi del Minvu que dispone la prórroga de la postergación de permisos estaba sujeta o no al control previo de legalidad que efectúa el organismo contralor, señaló que:

"Los actos administrativos dictados en cumplimiento de lo dispuesto en el artículo 117 de la Ley General de Urbanismo y Construcciones, están afectos al examen previo de juridicidad, por cuanto regulan materias esenciales relacionadas con las aprobaciones y modificaciones de los planos reguladores, tanto comunales como intercomunales, los cuales expresamente se han incluido dentro de los asuntos que deben cumplir con dicho trámite ante este organismo contralor".

Por tanto -si bien la simple postergación inicial de permisos se decreta por el propio alcalde con un informe previo y favorable del seremi de Vivienda materializado en un oficio cuya legalidad no es controlada por CGR- toda prórroga de la postergación decretada mediante decreto supremo del MINVU debe ser objeto del trámite de toma de razón.

\subsection{División de Desarrollo Urbano del Minvu (DDU)}

La División de Desarrollo Urbano del MINVU es un órgano de mucha relevancia para la aplicación oficial de las normas urbanísticas.

Dice el artículo $4^{\circ}$ de la Ley General de Urbanismo y Construcciones:

Al Ministerio de Vivienda y Urbanismo corresponderá, a través de la División de Desarrollo Urbano, impartir las instrucciones para la aplicación de las disposiciones de esta Ley y su Ordenanza General, mediante circulares, las que se mantendrán a disposición de cualquier interesado. Asimismo, a través de las secretarías Regionales Ministeriales, deberá supervigilar las disposiciones legales, reglamentarias, administrativas y técnicas sobre construcción y urbanización e interpretar las disposiciones de los instrumentos de planificación territorial.

El legislador ha querido entonces que sea la División de Desarrollo Urbano la encargada de impartir instrucciones sobre la aplicación de la Ley y de su ordenanza general.

Se revisan entonces sus interpretaciones en materia de postergación de permisos. 
5.2.1 Circular No 2 (1989). Restricción temporal de la iniciativa privada, imposibilidad jurídica de áreas de congelamiento permanente y excepcionalidad del artículo 117 de la LGUC

Esta circular vuelve a reiterar los criterios de la CGR en relación a la naturaleza jurídica del artículo 117 de la LGUC. La califica como "una disposición restrictiva que afecta el derecho de propiedad", y es en razón de aquello que la ley "ha establecido plazos cortos y definitivos a fin de no entorpecer la acción privada".

Fundado en su carácter excepcional, la autoridad municipal solo está facultada para decretar congelamientos que no excedan el plazo de doce meses.

"Transcurrido el referido plazo, el decreto de suspensión o la resolución según corresponda se extingue por el solo ministerio de la ley, no permitiendo prórroga de ninguna naturaleza".

Por tanto, el término de la prórroga de un congelamiento no requiere de ninguna clase de acto administrativo que la certifique; basta para su extinción el solo transcurso del plazo correspondiente.

Es interesante que la circular en cuestión genere una respuesta ante un problema que podría llegar a plantearse: ¿Qué ocurre si un particular presenta una solicitud de permiso -ya sea de subdivisión, loteo o urbanización- que recae sobre un área que es objeto de estudios en torno a una posible modificación del plano regulador? En la medida en que aún no se haya decretado el correspondiente congelamiento, la Dirección de Obras Municipales deberá pronunciarse derechamente sobre ellos.

Concluimos que esta circular:

a) Reitera la idea que los congelamientos urbanísticos tienen un alcance restrictivo en cuanto a su contenido y limitado en relación a sus efectos. Ello porque significan -por vía administrativa- establecer restricciones al derecho de propiedad de los particulares. Consciente de aquello el legislador, ha establecido plazos breves y restringidos, cuya ampliación sería derechamente inconstitucional;

b) Señala claramente que toda prórroga de un congelamiento se extingue ipso iure por el solo transcurso del plazo fijado por la ley, sin que se requiera un acto administrativo de naturaleza declarativa que así lo indique; y

c) Declara que -dado el alcance excepcional y restrictivo de esta institución- la sola existencia de estudios de posibles modificaciones al plano regulador comunal o intercomunal no justifican que la Dirección de Obras municipales no se pronuncie en torno a los permisos solicitados por particulares. Solo podrá suspenderse este pronunciamiento en caso que exista un decreto alcaldicio que declare el congelamiento expresamente.

5.2.2 Informe $N^{o}$ 17/94. Oficio Circular $N^{o} 16$ (1994). Exigencias de oportunidad en la solicitud de prórroga. Proscripción de modificación de áreas con el objeto de burlar los plazos de la ley

Esta circular básicamente se refiere a dos puntos. El primero de ellos dice relación con la exigencia de oportunidad en la solicitud de la prórroga. En cuanto el plazo 
máximo contemplado por la ley para un congelamiento es de doce meses, el espíritu de la ley obliga a la autoridad interesada a solicitar la prórroga en tiempo oportuno:

"Es importante que la oportunidad en que se hace la postergación de permisos corresponda a una etapa en la que la Municipalidad ya tenga definido el contenido de la norma local que se desea modificar y que haya sido concordado en sus aspectos normativos generales con esta Secretaría Ministerial"

Y en cuanto la posibilidad de que sean modificados los planos reguladores comunales para efectos de alterar las áreas urbanas y así extender artificialmente un congelamiento, la DDU mantuvo la doctrina del dictamen No 4.358 de CGR:

"Asi también es necesario recalcar que los plazos de postergación de permisos y sus prórrogas no se pueden extender más allá del periodo indicado precedentemente recurriendo al expediente de modificar parcialmente los limites del área en que desea aplicar dicha disposición".

En consecuencias serían ilegales:

a) Toda autorización de prórroga del SEREMI de Vivienda que se funde en una solicitud extemporánea o intempestiva de la autoridad municipal; y

b) Cualquiera resolución que permita congelar los permisos que recaen sobre áreas respecto de las cuales ya ha recaído un congelamiento previo, todo ello vía modificación del plano regulador respectivo.

\subsubsection{Circular Ordinaria No 7 (1996): Imposibilidad de decretar congelamientos} genéricos y plazos

Por medio de esta circular, el Jefe de División de Desarrollo Urbano del MINVU instruye acerca del procedimiento administrativo relacionado con los congelamientos. Junto con reiterar el carácter excepcional de la medida así como su régimen de interpretación restrictiva, señaló que:

"Su vigencia no puede superar el plazo de tres meses, sin perjuicio de su prórroga, y en todo caso debe referirse a sectores específicos de la comuna en que las normas van a ser alteradas por los instrumentos reguladores del desarrollo urbano que se encuentran en estudio".

Asimismo, la DDU reconoce que en relación a la prórroga del congelamiento la ley ha establecido que este puede extenderse hasta un máximo de doce meses,

"vale decir, en este plazo deben incluirse los dias transcurridos de los tres meses de postergación dispuesta por resolución del alcalde”.

Por tanto, todo congelamiento puede extenderse como máximo hasta doce meses; la prórroga solamente podrá abarcar nueve meses a partir del término del congelamiento primitivo. 
En cuanto a la oportunidad en que el alcalde debe solicitar la autorización de la prórroga al SEREMI correspondiente, el DDU señala que:

"Es conveniente destacar que la ley no otorga al Ministerio de Vivienda y Urbanismo facultades para fijar un nuevo plazo de postergación de permisos; sino que solo tiene atribuciones para prorrogar el plazo fijado por el alcalde. Por ello, mientras este se encuentra pendiente y con la debida anticipación, debe gestionarse la prórroga del plazo, ya que de no hacerlo oportunamente el Ministerio de Vivienda y Urbanismo quedaría impedido de dictar un decreto supremo de prórroga".

¿Podría entonces un alcalde solicitar la autorización de la prórroga hacia el final del período o los últimos días de vigencia del congelamiento? La respuesta es no. Se requiere que la presentación sea tramitada dentro de un plazo prudente, que permita al Seremi correspondiente conocer y resolver la cuestión dentro del plazo de los tres meses.

$\mathrm{Y}$ ¿qué ocurre en relación a los permisos solicitados por los particulares si antes que se pronuncie el seremi vence el plazo original de tres meses? De acuerdo a esta circular:

"Deberán admitirse a tramitación los permisos solicitados aún cuando esté pendiente la tramitación de la prórroga si fuere el caso, que esta solo opera una vez que se publica en el Diario Oficial el decreto supremo respectivo".

Podemos concluir, entonces que:

a) Todo congelamiento requiere de precisión en su determinación;

b) Toda solicitud de prórroga del congelamiento debe ser efectuada por al alcalde dentro de los tres meses del plazo original y, de autorizarse, solo abarcaría los nueve meses siguientes;

c) El gestionamiento de la solicitud debe ser efectuado oportunamente dentro de los tres meses correspondientes, de tal manera que el seremi pueda estudiar debidamente los antecedentes del caso; y

d) Si estando pendiente el pronunciamiento del SEREMI vence el primitivo plazo de tres meses del congelamiento, entonces la Dirección de Obras de la Municipalidad correspondiente deberá pronunciarse derechamente respecto de los permisos ya solicitados por particulares.

\subsection{CONCLUSIONES GENERALES DE LA JURISPRUDENCIA ADMINISTRATIVA}

A partir de los diversos pronunciamientos administrativos revisados podríamos extraer como conclusiones que:

a) Todo congelamiento urbanístico es de naturaleza excepcional, en cuanto significa suspender el ejercicio del derecho de propiedad de una persona sobre un área determinada;

b) Por lo mismo, esa suspensión tiene un alcance temporal limitado: no puede exceder de los doce meses, incluyendo una potencial prórroga en ella. Cualquier congelamiento indefinido es ilegal;

c) Es imperativo - dada la naturaleza excepcional de la institución- que la autoridad competente solo autorice congelamientos precisos y determinados, nunca genéricos; 
d) En relación a la prórroga de un congelamiento cabe señalar:

- Solo pueden ser solicitados oportunamente por el alcalde al SEREMI dentro del plazo de los tres meses originales;

- Es ilegal que la autoridad se sirva de cualquier arbitrio jurídico destinado -ya sea por vía directa o indirecta- a prorrogar un congelamiento más allá de doce meses; y - La prórroga cesa ipso iure por el solo transcurso del plazo, sin necesidad de requerir de un acto administrativo declarativo adicional;

e) Una vez cesada la prórroga, corresponde a la Dirección de Obras Municipales -en virtud del artículo 118 de la LGUC- pronunciarse derechamente acerca de los permisos solicitados; $y$

f) La existencia de estudios para una potencial modificación del plano regulador comunal o intercomunal no es causa suficiente para que la Dirección de Obras Municipales se abstenga de pronunciarse en torno a los permisos solicitados. Solo es causa suficiente la existencia del decreto correspondiente de congelamiento.

\subsection{JURISPRUDENCIA DE LAS CORTES SOBRE CONGELAMIENTOS. POTESTAD IN- VALIDATORIA, DERECHOS ADQUIRIDOS E ILEGALIDAD DE CONGELAMIEN- TOS PERMANENTES}

Las cortes de justicia han tratado los congelamientos con ocasión de conflictos sobre invalidación, derechos adquiridos y abusos en los plazos.

Revisaremos la jurisprudencia publicada en la materia.

\subsubsection{Caso "Zapallar" (1994)18: Inconstitucionalidad de los congelamientos permanentes}

En este caso, los hechos son los siguientes:

La sociedad inmobiliaria "Los Hermanos S.A." era dueño de un terreno en Cachagua. Hacía dos años que había iniciado gestiones ante la Dirección de Obras de la Municipalidad de Zapallar para obtener autorización para subdividir, lotear y urbanizar esos terrenos. Sin embargo, a partir de 1991 el alcalde había dictado decretos de congelamiento sucesivos que habían impedido pronunciarse acerca de los permisos solicitados. Ello motivó que la sociedad interpusiera un recurso de protección ante la Corte de Apelaciones de Valparaíso invocando la afectación del derecho de propiedad y el derecho a desarrollar actividades económicas lícitas.

La Corte acogió el recurso y señaló:

"Considerando 6". Que, con los documentos acompañados por la recurrente se encuentra acreditado que la I. Municipalidad de Zapallar no se ha pronunciado dentro del plazo legal respecto de los proyectos de subdivisión, loteo y urbanización (...) y ha prorrogado mediante la dictación de sucesivos decretos, por más de doce meses, plazo

18 Sociedad inmobiliaria Los Hermanos S.A con Dirección de Obras de Municipalidad de Zapallar (1994). 
máximo que autoriza el artículo 117 de la LGUC (...) la postergación de dichos permisos, actuación esta que resulta ilegal y arbitraria y ciertamente conculca el derecho de propiedad en sus diversos atributos que confiere la ley al propietario recurrente, toda vez que ha congelado las posibilidades de goce y disposición de la propiedad por parte de aquel, por lapso superior al permitido por la ley, razón por la que cabe acoger el recurso de protección".

Confirma, entonces, la Corte el criterio administrativo en la materia: De acuerdo a la naturaleza excepcional de todo congelamiento, no corresponde ampliarlo directa o indirectamente por un período superior a los doce meses.

\subsubsection{Caso "San Pedro de Atacama" (1998)19: Ilegalidad de congelamientos} fundados en fraude a la ley

En este caso, un empresario era dueño de un terreno en las afueras de la comuna de San Pedro de Atacama. Con la intención de destinar ese terreno a fines turísticocomerciales solicitó al SAG el cambio de uso de suelo, solicitud que fue resuelta favorablemente. Sin embargo, el alcalde dictó un decreto que congeló o postergó los permisos de subdivisión, loteo o urbanización predial y de construcciones en toda la comuna. Tras obtener la prórroga del congelamiento, el alcalde decidió decretar el congelamiento del sector de la comuna que era el objeto del permiso del empresario.

Ante ello, el afectado recurrió a la Corte de Apelaciones de Antofagasta, la que acogió el recurso. Señaló el tribunal:

"Considerando 4". (...) Del tenor literal de la norma transcrita [artículo 117 de la LGUC] se infiere que el referido artículo es de carácter excepcional y, por lo tanto, de interpretación restrictiva, de tal modo que el plazo de postergación de los permisos de loteo, subdivisión o urbanización y de construcciones, no pueden exceder de doce meses, más allá de los cuales los efectos de los Decretos de suspensión se extinguen por el solo ministerio de la ley, no admitiendo prórrogas de ninguna especie”

Y agrega dentro del mismo considerando:

"Ni [admiten] tampoco la figura jurídica de dictar un nuevo decreto que afecte a parte del mismo sector -ya sometido a suspensión-lo que involucra una superposición de sectores que vulnera el espiritu del legislador al dictar la norma en comento, ya que respecto del mismo terreno podría existir la imposibilidad de obtener los referidos permisos por un periodo superior a un año".

Caben dos observaciones a esta jurisprudencia: Una vez más se reconoce el carácter excepcional de todo congelamiento urbanístico, fundado en que implica "dejar un bien fuera del comercio humano". Esto justifica el alcance restrictivo de toda interpretación del artículo 117 de la LGUC. Y de aquí surge la segunda observación: Los órganos administrativos que participan de estas decisiones no podrán utilizar mañosa o fraudulentamente

19 Poblete Alay con Dirección de Obras de Municipalidad de San Pedro de Atacama (1998). 
un instrumento normativo de carácter excepcional. Si lo hicieren, la disposición iría más allá de lo que la ley permite al administrador intervenir en el derecho de propiedad, por lo que el acto quedaría fuera del marco predeterminado por la ley habilitante.

5.4.3 Caso "anulación de permisos" (1999)20: Inconstitucionalidad de la invalidación de permisos de construcción otorgados aún si media congelamiento Con fecha 26 de febrero de 1998 la Dirección de Obras de la Municipalidad de Viña del Mar aprobó un permiso de obra nueva a una empresa constructora. Ello, pese a que el 2 de diciembre de 1997, se había decretado el congelamiento de los permisos en el área respectiva. Esto motivó que la Municipalidad invalidara el 6 de octubre de 1998 los permisos otorgados.

La afectada recurrió entonces de protección ante la Corte de Apelaciones de Valparaíso, la que acogió el recurso. Son de sumo interés los considerandos $5^{\circ}, 6^{\circ}$ y $7^{\circ}$ de la sentencia:

"Considerando 5". Que no resulta posible aceptar la tesis juridica que el referido Director (...) esté investido de tal facultad que le sea posible invalidar resoluciones a actos suyos que hayan producidos efectos juridicos, habida cuenta que se trata, en el caso de la persona por quien se recurre, de alguien que ha estado de buena fe, circunstancia que no ha sido discutida, ya que a consecuencia del acto jurídico del Director de Obras se incorporó al dominio el derecho que le otorgaba ese permiso, esto es, el derecho a construir un edificio de las características que en él se indican, derecho que se encuentra amparado por el articulo $19 N^{\circ} 24$ de la Constitución Politica de la República y que puede ser protegido por esta acción";

Considerando 6०., Que, además de lo anterior cabe consignar que los actos administrativos no pueden revocarse en forma unilateral por la administración en general, y la comuna, en particular, invocándose como fundamento para actuar asi errores propios, ya que estos solo le afectan a ella, especialmente si el acto administrativo, tal como se indicara, ha hecho nacer derechos patrimoniales que han adquirido terceros que han obrado de buena fe, los que están amparados por la garantía constitucional ya indicada";

Considerando $7^{\circ}$. Que, también debe tenerse presente que no se ajusta al Derecho en su actuar, quien habiendo sido autor de un acto administrativo al que pueda imputársele un vicio pero que ha generado derechos para sus beneficiarios, adopta él mismo una resolución que tenga por finalidad dejar sin efecto su acto; ya que esa medida no es de competencia del autor del acto, sino del juez, al tratarse de un asunto jurisdiccional; ya que será el tribunal, a través de un debido proceso, quien sentenciará si hubo o no vicios en el acto cuya invalidación se pretende".

Podemos, a partir de la lectura de estos considerandos, extraer las siguientes conclusiones:

${ }^{20}$ V.S.L con Dirección de Obras de la Municipalidad de Viña del Mar (1999) 
a) Los actos administrativos favorables - como un permiso urbanístico- crean para el particular una situación jurídica sobre la cual tiene un derecho de propiedad, aun cuando la hubiere mediado error y siempre que el beneficiario esté de buena fe;

b) No podrá, entonces, la Administración derechamente invalidar esta clase de actos fundada en que cometió un error;

c) Aplicando estos principios a los congelamientos urbanísticos, si la autoridad municipal erróneamente confiere permisos durante períodos de congelamiento, no podrá invalidarlos unilateralmente; $y$

d) Corresponde al órgano jurisdiccional -dentro del marco de un debido procesoconocer del caso concreto y determinar si existió o no error de la Administración y si existía respecto del particular buena fe.

\subsubsection{Caso "Sociedad clinica Iquique" (2001)21: Interdicción de la} arbitrariedad en materia urbanistica

Aquí, la sociedad "Iquique S.A" era propietaria de una clínica, que decidió ampliar. Para ello solicitó los correspondientes permisos de ampliación, los que fueron otorgados por la Dirección de Obras Municipales de la Municipalidad. Sin embargo, al momento de solicitar el certificado de recepción de obras el año 2000, la Dirección le informó que su permiso se encontraba congelado "por existir de parte de la Seremi de Vivienda y Urbanismo una solicitud de revocar tal permiso".

Ante esta situación, el particular recurrió de protección, la que fue acogida. Señaló la Corte:

"Considerando 15". Que es del caso destacar que ni la Ley orgánica de Municipalidades, ni la Ley de Urbanismo y Construcción, su Ordenanza General, ni el Plano regulador ni texto legal similar han otorgado a la Dirección de Obras Municipales facultad alguna para congelar y menos para invalidar permisos de construcción concedidos que hayan producidos sus efectos propios, esto es, construir las obras para lo cual fueron solicitados;

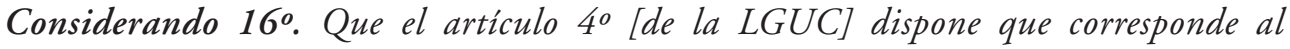
Seremi supervigilar las disposiciones legales, reglamentarias, administrativas y técnicas sobre construcción y urbanización (...);

Considerando $17^{\circ}$. Que las facultades de que están investidas las autoridades en modo alguno pueden ejercerse en forma arbitraria o discriminatoria, su ejercicio debe ser legitimo, lo que implica que debe ajustarse a criterios de legalidad constitucional, de oportunidad, proporcionalidad y de legitimidad lógica (...) Toda facultad discrecional debe ser ejercida con estricta sujeción a antecedentes de becho fidedignos y considerando además la oportunidad y el perjuicio que de ello pueda irrogarse a las personas involucradas, no puede actuarse arbitrariamente haciendo un uso no razonable de facultades jurídicas, ni excederse más allá del fin que fue previsto

21 Sociedad clinica Iquique S.A con Dirección de Obras de Municipalidad de Iquique (2001). 
por el legislador, debiendo en todo caso ajustarse la actuación discrecional a principios lógicos elementales";

A partir de este fallo, concluimos que:

a) La autoridad administrativa para proceder a congelar permisos debe cumplir con dos presupuestos:

- Uno, formal. Este dice relación con el cumplimiento de los trámites y procedimientos establecidos en la ley; y

- Un segundo, de carácter sustancial. Se requiere que en su actuación la autoridad opere de forma razonada y razonable. Por tanto, todo congelamiento fundado en antecedentes inexactos, cuya motivación fuera viciada o bien se apartara del fin señalado por el legislador sería inconstitucionales al infringir el artículo 19 No 2 de la Constitución Política.

\subsection{CONCLUSIONES GENERALES DE LA JURISPRUDENCIA JUDICIAL}

A partir de la lectura de los fallos presentados, podemos entender que:

a) La postergación de permisos opera en un plano excepcional y restrictivo. Luego, su constitucionalidad no pende del mero cumplimiento por parte por la autoridad de los requisitos formales exigidos por el artículo 117 de la LGUC, sino que, agregamos nosotros, también de requisitos materiales, relacionados con el respeto del principio de interdicción de la arbitrariedad. En este sentido, solo los estudios de modificación al Plan regulador justifican su imposición.

b) Todo congelamiento deberá respetar los derechos adquiridos de los particulares. Esto es, si erróneamente la Administración confirió un permiso a un particular de buena fe, este producirá todos sus efectos y no podrá ser unilateralmente dejado sin efecto por los organismos administrativos;

c) Tiene carácter ilegal e inconstitucional todo congelamiento de carácter permanente, ya que esa idea repugna al plazo máximo de doce meses determinado por la LGUC; y

d) Es inconstitucional toda fórmula jurídica que permita a la autoridad administrativa extender artificialmente los plazos legales de congelamiento, como, por ejemplo, empleando modificaciones intempestivas de planos reguladores o seccionales que permitan decretar nuevos congelamientos sobre las mismas áreas anteriormente afectas al mismo.

\section{CONCLUSIONES}

A partir de los antecedentes revisados y las consideraciones efectuadas anteriormente, pueden extraerse las siguientes conclusiones:

1. El mecanismo de las postergaciones o congelamiento de permisos urbanísticos (subdivisión, loteo y construcciones) del artículo 117 de la Ley General de Urbanismo y Construcciones, configura un régimen excepcionalmente limitativo del derecho de pro- 
piedad. Las postergaciones comprimen por plazos excepcionalmente largos -bajo estándares constitucionales- las facultades esenciales del titular del dominio sobre su inmueble y sobre su respectivo permiso.

2. Las postergaciones de permisos provienen del texto original del artículo 117 del DFL 458, de 1975, y son difícilmente compatibles con la Constitución de 1980, dictada posteriormente. La incompatibilidad emerge con el nuevo texto y algunas sentencias del Tribunal Constitucional que se han pronunciado sobre la esencia del derecho de propiedad (Rentas Vitalicias, rol 334, de 21 de agosto de 2001) y otras recientes de la Corte Suprema que potencian el derecho de propiedad sobre los permisos urbanísticos (CDUC con Contralor, rol 2224-2006).

3. Aún si se admite la constitucionalidad de los congelamientos, su carácter excepcionalmente gravoso obliga a las autoridades administrativas que lo decretan o prorrogan -alcalde y seremi del MINVU- a lo siguiente:

a. A interpretar restrictivamente los elementos de hecho y de derecho que justifican en cada caso su procedencia; y

b. A fiscalizar rigurosamente los presupuestos legales de fondo que lo justifican y no solo aquellos meramente formales.

4. Estando la autoridad administrativa obligada a fiscalizar los requisitos de fondo exigidos por la ley para decretar o prorrogar un congelamiento, resultará esencial que cada postergación se funde en:

a. estudios reales, ciertos, concretos y actuales sobre modificaciones inminentes (previstas para operar en no más de tres meses) al Plan Regulador respectivo, como condición previa y no posterior para decretar el congelamiento;

b. casos necesarios y calificados, derivados de circunstancias imprevistas en un comienzo, como elemento indispensable para decretar la prórroga de la postergación, la que debe en todo caso calificarse caso a caso y no adelantarse desde un inicio.

5. Repugna a una interpretación sistémica del artículo 117 de la LGUC en su relación con el artículo 19 No 24 de la Constitución el que, con ocasión de una modificación al Plan Regulador en un futuro mediano, y previendo el inicio de los estudios para ello, el alcalde y el seremi validen desde un comienzo postergaciones de permisos por el plazo máximo de un año, calculando este período como cierto en sus cronogramas y anticipando tácitamente cuatro postergaciones de permisos que no serán apreciadas caso a caso, como exige la ley.

6. Sin perjuicio de la exigibilidad de los referidos aspectos de fondo, es útil consignar que las Cortes de Apelaciones y de la Corte Suprema han fiscalizado preferentemente los requisitos formales de las postergaciones. En este ejercicio, su jurisprudencia ha rechazado anomalías como las superposiciones territoriales, las prórrogas superiores al máximo de un año, y todo otro arbitrio que persiga mantener a determinadas áreas 
congeladas mas allá del plazo máximo autorizado por la ley. La jurisprudencia también ha rescatado el derecho de propiedad sobre el permiso de edificación emitido antes del congelamiento y el derecho de su titular para obtener su recepción final. En la mayoría de estos pronunciamientos, las sentencias han reiterado el carácter excepcional de las postergaciones, lo que hace prever que se irá avanzando en analizar crecientemente la concurrencia de los presupuestos de fondo previstos por la ley.

\section{BIBLIOGRAFÍA CITADA}

1. Fermandois, Arturo (1997): "Discrecionalidad urbanística y garantías fundamentales”, Revista Chilena de Derecho, vol. XXV, pp. 243-248.

2. FERMANDOIS, Arturo (2005): "Inaplicabilidad de la ley de monumentos nacionales: hacia la inconstitucionalidad de la expropiación regulatoria en Chile”, en: FERMANDOIS, Arturo (edit.), Sentencias destacadas 2004 (Santiago, Libertad y Desarrollo) pp. $19-55$.

3. RAJEVIC, Enrique (2000): "Derecho y Legislación Urbanística en Chile", Revista de Derecho Administrativo Económico (2): pp. 527-548.

4. CAncino, Fernando (2005): "Consideraciones en torno a las Limitaciones al Dominio en Materia Urbanística”, Revista de Derecho Administrativo Económico, (15): pp. 159-170.

5. Tejedor, Julio (1999): "Propiedad, Urbanismo y Estado Autonómico", Revista de Administración Pública, (148): pp. 387-434.

\section{NORMAS CITADAS}

1. DS No 100, Constitución Política de la República, Diario Oficial, 22 de septiembre de 2005;

2. Ley No 17.288, Ley de monumentos nacionales, Diario Oficial, 4 de febrero de 1970;

3. DFL No 458, Ley general de urbanismo y construcciones, Diario Oficial, 13 marzo 1976 ;

4. Ley No 19.300, Bases generales del medio ambiente, Diario Oficial, 9 de marzo de 1994 ;

5. Ley No 19.744, Flexibiliza congelamientos de terrenos, Diario Oficial, 10 de agosto de 2001;

6. Ley No 19.880, Bases generales de los procedimientos que rigen a la administración pública, Diario Oficial, 29 de mayo de 2003;

7. Ley No 19.939, Diario Oficial, Establece caducidad de la declaratoria de utilidad pública contenida en los planes reguladores, Diario Oficial, 13 de febrero de 2004.

\section{JURISPRUDENCIA JUDICIAL CITADA}

1. Los Hermanos S.A. con Dirección de Obras de la Municipalidad de Zapallar (1994): Corte de Apelaciones de Valparaíso, 25 de mayo de 1994 (recurso de protección), en: Сово, Pedro (2005): Ley general de urbanismo y construcciones (Santiago, Editorial LexisNexis), 2.030 pp. 
2. Viviendas 2000 Limitada con Alcalde de Municipalidad de Lo Barnechea (1997): Corte de Apelaciones de Santiago (recurso de protección), Rev. chil. derecho, vol. XXV, pp. 243-248;

3. Poblete Alay con alcaldesa de Municipalidad de San Pedro de Atacama (1998): Corte de Apelaciones de Antofagasta, 24 de noviembre de 1998 (recurso de protección), Revista de Derecho y Jurisprudencia, tomo XCVI (1999), II, sección 5a, pp. 50-56;

4. V.S.L con Dirección de Obras de la Municipalidad de Viña del Mar (1999): Corte de Apelaciones de Valparaíso, 29 de julio de 1999 (recurso de protección), CoBO, Pedro (2005): Ley general de urbanismo y construcciones (Santiago, Editorial LexisNexis), $2.030 \mathrm{pp}$.

5. Sociedad clinica Iquique S.A con Dirección de Obras de la Municipalidad de Iquique (2001): Corte de Apelaciones de Iquique, 7 de marzo de 2001 (recurso de amparo económico), en: COBO, Pedro (2005): Ley general de urbanismo y construcciones (Santiago, Editorial LexisNexis), 2.030 pp.

6. Inmobiliaria Maullín con Fisco (2004): Corte Suprema 18 junio 2004 (recurso de inaplicabilidad), en: Rev. Derecho (Valdivia), vol. XVII, pp. 215-226;

7. Tribunal Constitucional, [fecha de consulta: 4 de junio de 2007]. Disponible en: http://www.tribunalconstitucional.cl/site/sentencias/anos/2001/html;

8. Tribunal Constitucional, [fecha de consulta: 4 de junio de 2007]. Disponible en:http://www.tribunalconstitucional.cl/site/sentencias/anos/1993/html;

9. Tribunal Constitucional, [fecha de consulta: 4 de junio de 2007]. Disponible en:http://www.tribunalconstitucional.cl/site/sentencias/anos/1985/html.

\section{JURISPRUDENCIA ADMINISTRATIVA CITADA}

1. Contraloría General de la República, Dictamen No 4.358, 9 de febrero de 1989;

2. Contraloría General de la República, Dictamen No 10.694, 28 de marzo de 1994;

3. Contraloría General de la República, Dictamen No 38.990, 1994.

4. División de Desarrollo Urbano (MINVU), Circular ordinaria No 7, 4 de agosto de 1986;

5. División de Desarrollo Urbano (MINVU), Circular No 2, 3 de marzo de 1989;

6. División de Desarrollo Urbano (MINVU), Oficio circular No 16, 6 de junio de 1994. 
